SHS Web of Conferences 14, 02018 (2015)

DOI: $10.1051 /$ shsconf/20151402018

(C) Owned by the authors, published by EDP Sciences, 2015

\title{
A Study on the Establishment and Development Status of Sub-business Zone at Chinese University Economy
}

\author{
Xinxi Jiang ${ }^{1}$, Minwen $\mathrm{He}^{1}$ and Wei Zhang ${ }^{2}$ \\ ${ }^{1}$ Professor of Business School, Jiangxi Normal University, 330022 Nanchang Jiangxi, China \\ ${ }^{2}$ School of Intercultural Studies, Jiangxi Normal University, 330022 Nanchang Jiangxi, China
}

\begin{abstract}
This paper initially studied the formation and development of the derived economic ring circling university induced by university's operations. University operations are associated with specific economic externalities; mainly due to that university has a strong cash flow which causes the effect of pooling of business resources. In all aspects, Capital flow movement is the most active operating resource succession in the ring, and is one of the academic fields worthy of extensive research. Forward induction and reverse incubation are effective useful approaches for university operators to form the derivative economic ring in practice.
\end{abstract}

Keywords. university economy; sub-business zone; external economy; capital-flow

\section{Introduction}

Knowledge economy and knowledge industry have become indispensable innovation in the 21 st century. Business operation and district operation (e.g. city operation) have developed into university operation and society operation. University operation is developing gradually from simple education economy to multiple economies which include rear services industry, technology industry, culture industry and education industry. The special function of university knowledge economy brings the industry environment special develop path, that is forming the sub-business zone of university operation. This kind of phenomenon is just the "economic externality" in theoretical economics. And yet, the common essence of "externality" is the objective demand from society to the university, which is the origin of the economic externality. It is reflected in the process of pursuing not only the education function but also external economic function of university operation.

Make a study of formation and development discipline of the sub-business zone can help the university to transform knowledge production achievement. What's more, it can guide the university to expand external income of knowledge economy on its own. In addition, the sub-business zone of university operation besides an external presentation, which is that the 21 st university will become the center of industrial cluster's formation. University will play an important role to drive the regional economy in the future.

\section{Concepts}

\subsection{A case at front}

In 1979, the ministry of forestry decides to move the Central South Forestry University from Xupu County, Dajiang Kou of West Hunan to the suburb of Zhuzhou, Tianxin Area (this place is a hills and mountains called "Zhang Shu Xia"). After three years, a piece of hill type area covered by oil-tea trees became the head office of a university. Around the year of 1995, the resident building and service facility had more luxurious extent than the head office, and the living standard of local folks is similar with the university professor. In 1998, the university teachers admired the local folks' lives. They immediately joined the group of surrounding university operation. The situation of composition operation appeared. After years of cooperation, some of those operators around had become the staff of the university; some had become the cooperators of school operation, even though some had become investors. Other universities in Hunan province also have this kind of phenomenon.

\subsection{Some concepts needed in the research}

University operation is a knowledge economy category; it has two senses of operation resource growth and sustainable development. The growth of university mainly depends on the growth of university operation resource. In general, the factors of operation resource include: human, financial, material resources, time, information, relationship and space. Because the character of university operation resource depends on itself qualitative prescription, its growth belongs on "endogenous growth" in the economics. The systematic and coordination between each uni-

This is an Open Access article distributed under the terms of the Creative Commons Attribution License 4.0, which permits unrestricted use, distribution, and reproduction in any medium, provided the original work is properly cited. 
versity operation resource is objective base of scientific development. From the sustainable development of view, university development mainly depends on the coordinate development of resource, technology, economic mechanism and market. On the other hand, as a public utilities organization, university has typical external economy function, which can emerge multifaceted operation action to form a radial economy circle at the university. It has all kinds of economy relationship in the circle. These relationships can be explained by the basic concepts below:

\section{Associate and coopetition}

Associate means the causal relationship or primarysecondary relationship between the operation subjects or projects, such as undergraduate family tutor, examine assistance. Because of the two organizations around the university, it produces two results: raise the enrollment rate, increase operating income. Operating the same or similar projects will result in competition, such as the student canteen and the eating house around the school. However, internet bar and the eating house have cooperative relationship, so as the dancing hall and the eating house. The internet bar and dancing hall have subtle competitive relation. Competition is a concept of competitive cooperation. The competition between subjects or projects can get homogeny profit; its origin is the restricting of general budget from consumer. Associate is effective coordination or complementation between the operating projects. Its origin is to satisfy promptly the different consume demand of consumers.

\section{Nonreversible accumulation}

Toward currency accumulation, the knowledge accumulation is different, which includes information and culture accumulation. Its basic character is nonreversible accumulation. This character is the reason of "man struggles upwards" and the base of whether to accept the operators' service or not. The different consuming behaviors between new and old students are on the basis of different degrees of knowledge accumulation.

Knowledge cannot accumulate in a reverse way, this is determined by the characteristics of the relationship between human and practice, and knowledge system's own features. Therefore, knowledge accumulation is the most important and active factor in the capital accumulation. It can be note worthy that: those universities which establish subjects of operate and manage can speed up reformation of the sub-business zone of university. That is because the nonreversible accumulation of operate and manage knowledge can drive the study of operators around the universities.

\section{External economy}

Operation of the university has typical external economy. The development of university gives economic benefit (welfare) to not only the university operators but also the operators around the university. With the strength and subject character, the university would form industry belt (industry group or industry area) toward some special directions of operation. At last, the belt makes up a part of the regional economy.

Because of the external economy, many local governments enroll local higher education to the regional development. They try their best to promote all-win of the university and these places.

\section{Derive and symbiotic}

The main course can derive branch and boundary course in the university. Than, each college and research laboratory form. Similarly, the main careers of university operating can also derive all kinds of small operating domain. These groups are associated and different with the university operators. The link of university operation extends constantly. Operating mechanism changes constantly. Operating performance enlarges and deepens constantly. Its contribution and influence toward local economy is enlarging constantly. Look from this kind of meaning, the formation of university sub-business zone is a necessary result of university knowledge economy.

\section{The phenomenon description of the sub-business zone}

How to utilize specific things to express the phenomenon of University operations sub-business zone? Following, will from five aspects to state it.

\subsection{Side effects of accumulation of resources (dynamic equilibrium)}

"Excess resources" is another expression of the side effects of accumulation of resources, such as "overstaffing" is the synonymous of relative surplus of human resources. The relative surplus of human resources of University has a special mode of expression, such as type of activities of teachers; types of activities of cadres like stake in the business school project, high leisure activities. Relative surplus of funds resources is reflected in reliance on bank financing, does not focus on the rationality of internal cash flow, that lead to the financial cost too high and by borrowing to maintain operations; But, the more formal phenomenon of the university operator is the relative surplus of time except university leaders who busy in sea of papers and meetings, it is in sharp contrast to compare with the business community in the "time is money" phenomenon; The middle management of university usually have a lot of time outside the management work each year, but the effective resources of management they occupied are very impressive (a lot of time in idle state).

From the side effects of accumulation of operating resources, people get the reflection, the conclusion is: University, as business entities, the resources they difficult to use can provide business opportunities for the surrounding business entities. That is, many parts of the University management resources can provide business opportunities and benefit to the University departments or individuals, affiliates of University, group and personal around school.

In recent years, the University building trend provides tremendous opportunities for development to real estate investors. Every related fields of University curriculum development, assessment of teaching quality, the transformation of knowledge, all penetration of the operating 
elements of the "commercial and socialization", and showing a flourishing prosperity. The industries derived from featured disciplines involves in wider, such as some business projects associated with teachers of School of Finance, like financial services, management consulting and so on; and some business projects set up by various college administrative departments, like graduates' venture and employment Service, public information services and so on. Without exception, all of them related to the side effects of the growth of University management resources.

Bookstores, clothing stores, logistics services, express delivery, rental services of transport and even flea markets, they are the essential business items around the university. Because these projects relevant to the needs of daily life of the university staff and students, and when the operation of the University of exist leakages or lack of reasonable operation, will quickly rise these business items around the University, being the necessary and reasonable add of University operation .

\subsection{Subsidiary resource (kindergarten, affiliated schools, affiliated hospitals, Subsidiary factory)}

The most dynamic and effective part of University management resources are subsidiary operating attached to the University, include various types of affiliated kindergartens, schools for the children (Subsidiary middle and high school), affiliated hospitals, and ancillary school-run factories (such as printing, food plants, etc.). The industries derived from the subsidiary resources of University, is an important window of college connect to the society, but also an important way to obtain benefits of college's staff and students from their own management resources. The affiliated hospitals of comprehensive University, is an indispensable "ATM", In general, one of the top three hospitals in large cities, their average annual operating income more than 500 million yuan, equivalent to the annual operating income of a local comprehensive University, the sufficient cash flow can support the capital investment of the University. School-run factory of University not only derived from the scientific and technological achievements of featured disciplines, but also rely on credibility of college's intangible assets. In general, University in support of the school-run factory, always priority to the limited support of tangible assets, and did not consider the returns of its intangible asset.

\subsection{Commercialization of business agent of edu- cation}

University before the 1990s, Principals who once lamented that "College is a large society, have everything expect the prison and crematorium without", but with the rapid development of higher education of Chinese, the tradition of college take on every social affairs can't adapt the college's own change and come into the socialization of University operation, the most efficient and effective way is the socialization of logistics services. Now the most college has achieved logistics services to the community transition expect pension or retired management, man- agement of student, population and family planning, security affairs.

Business enterprises engaged in the logistics services of University, their tacit goal is "bigger and stronger", "grow with the university", or even "control the University". To expand at the University Park (Campus) and periphery, is their long-term unremitting business strategic objective. Therefore, whether the old or new campus of University, or the regional location, always covered various corporate headquarters or branch offices associated with logistical services around the college, as "hunters" to wait the birth of new services for long-term, sharing or even monopolize logistics services business in the process of growth and development of the University.

\subsection{Socialization of logistic services}

During the process of operating university, some universities have a prior understanding of the original source of the external economy (this may due to its academic settings. Universities with economics and management are particularly sensitive in external economy), however, some universities passively accept the current situation. When universities have a full understanding of the selfoperating of external economy, their operating behavior will have a great change. Generally speaking, universities with a higher level of management will assess and reconstruct the related industries, to maximize the value of tangible and intangible assets. And only when their financial strength is not match or unbalanced with the operating level, university operators will reasonably seek compensatory business resources from the main bodies around, and to obtain operating benefits according to the division

\section{The derivative economic circle's for- mation path and scale analysis}

In the history of university's self-operating derivative business circle's formation process, different forming paths exist. So in the discussing of its forming path, there is not only one mode. What's more important is that its process of forming has a kind of alarming significant $t$ the derivative business circle. So in this paper, the author puts forward five kinds of forming mode as a base for further research as a reference.

\subsection{The missing of the system}

In the origin of modern university of our country, national university model (or state type) is the mainstream, while there is not very much private universities. So this paper mainly described the missing of the system according to the origin of national universities. Generally speaking, the system of university is not match with the industry management. That is, universities mainly depends on cause funds for operating, they are fully planned economic systems. In the budget of country and local autonomous agent, university's cause fund is included in the education cause founds budget of higher education project, its financial revenues and expenditures are restricted 
by the financial budget plan. As university's financial revenues and expenditures are under the supervision of the education department and the treasury department, and the mechanism of leadership which it has (such as university president or party' s chairman) is influenced by the election of the government in administrative way, university does not have a corresponding industry operating plan in the long-term development strategic plan and actual annual development plan. So there is a leakage in the system for the formation of university's derived economy.

Under the background of the leakage of the system, the increase of university staffs' personal development requirements (including family development needs), and students and their parents' material and cultural requirements, will cause the appearance of industry operating carrier, and so as to form the management system which can satisfies the demands.

\subsection{The conspiracy of cultural needs}

University is a distributing centre of excellent talents. The most striking feature of talents is the intercommunity of cultural identity. The development of excellent talents needs a corresponding humanistic environment as a background. The combination of talents and superior assets (including intangible assets) is the necessary condition of knowledge economy's sustainable development. When the talents of university, government and enterprise reach a agreement in the development of superior assets, a conspiracy of combining operating resources will be formed, and eventually contribute resources for each other, and cooperate to get the requiring superior assets in a ripe condition.

The cultural industry and software industry of university is a typical case. When arts professor become a master of talents, the relative cultural enterprises may fight to be his broker, and his biggest industry supporter may be some talents from the government. By this, art master's work can get maximum additional value. From the example above, we can know that the conspiracy of cultural needs means that, economic entities who in the position of cultural person reach an agreement, and produced a common way of behavior. The entities can not only form a spiritual life platform, but also combine resources for economic interests. This phenomenon which based on the common interests and common behavior can appear more easily in the missing of the system.

\subsection{The update and reception of knowledge}

Knowledge succession sometimes also is called as knowledge update. Knowledge succession itself constructs the "information flow" in economics. University's information resource is the nuclear resource of university operating. But whether the information resource can realize its business value or not is decided by the integrity of the means and the degree of usefulness. That means information can be useless if not use in time, and on the other hand, the vaster information zone one can master and use, the more value it can accumulate (or have a multiplier effect), and the information will not be useless because have used before. So, from the feature of the information we can see that, the higher degree of integrity university subject structure and level has the more value it can produce through valid using.

Because of this, people by using the surplus information (information that can be used repeatedly) that come from the university's knowledge update may create economic interest. Then one would get rich economic returns by renting the information to people who need this knowledge.

\subsection{Alma mater complex and gather roles}

A long history university has a thick traditional culture in which one indivisible part is alma mater complex that leaves behind by thousands of graduates. See from the management resources aspect, alma mater complex is a kind of relation resource that we can use. As a relation resource, the nuclear function of alma mater complex is that it can be the link in of business operating chain, gather other resource that be needed in the industry operation( people, finance, material, time, information, space), thus became a industry operating level with a cultural tendency surrounding the universities.

Alumni association and science and technology parks are platforms to deepen alma mater complex and role cluster effect. Because university's cultural development and the continuation of alumni emotion need economic support. University's sustainable development depends on the support of schoolfellows. The change from traditional culture to industry culture in university both depend on the alma mater complex and role cluster effect, and the practical ability of development. It is an important topic on operating derivative economic circle around universities, and still remain future exploration and research.

\subsection{The strengthen scientific and cultural indus- try}

The development of Chinese style higher education made universities import industry composition into the construction of universities. Especially in recent twenty years, the industrialization of higher education promotes the quickly formation of derivative economic circle around universities. If university as an industry system should include four types: education industry, logistics service industry, high-tech industry, cultural industry. Above them, the restriction towards education industry and logistics service industry from education department is bigger. It's a typical planed economic operating field, and has achieved a stable development. While high-tech industry and cultural industry received support from education department and science and technology competent authority, and became an important indispensable industry.

Now, the way which our country encouraged for university's industry management is fixing the available assets' (university's state-owned assets) investment risk, establishing a limited liability company for business. Its 
main goal is to maintain value and increment of stateowned property, and make university industry become an effective economic subject in the national innovation strategy, thus promote the development of economy and society. The strengthen policy support towards university's science and culture industry simulates and accelerates the formation of university's derivative economic circle. The paid use of intellectual property, owning shareholding of science and cultural enterprise, all improved a great degree of knowledge economy permeation in operating field, and by this making the university's derivative economic circle more perfect and a quicker development.

\section{The capital flow of derivative econom- ic circle}

In the derivative economic circle, generally there exist three kind of active flow: business flow, logistics flow, information flow. The core of business flow is capital flow which is the characteristic moving subject in the derivative economic circle, and need further discussion.

\subsection{The fight of regional culture---the first bucket of gold}

Just as what the paper have written above, university's cause funds and students' big cash flow are attractive field to operator. When enterprise operators (including entrepreneurs) take university as their target market to operate, they need to fight for a platform used for cultural communication with university. By sponsoring universities' research projects, scholarship, donating construction funds, donating money for alumni fellowship project and so on, they can enter into the platform. Generally speaking, universities' resource sharing can not tolerate trading by money, most of the time, one succeed by hidden commercial culture permeation. Operators firstly get university's trust after cultural communication, and then get government and business trust by using universities' various relation resource. When condition is mature, operators may participate directly into the university's construction project, and make a fortune.

The operating that taking under the background of university's cause funds and students' big cash flow, can get more financial institutions' support by rolling development. So, if one has a stable operating base around university, and his project gets government and university's recognition, he can get his first bucket of gold.

\subsection{Meet the special need--formation of differen- tiation market (the optimization of capital profits)}

Sine the university is a commercial area of high-educated people, personalized trend is greater than popularized trend, and no monopoly operating can succeed. Personalized service that can satisfies special need can achieve a business success more easily. The specific need of specific people in university decides the differentiation marketing in operating strategy. Only when the operator chooses a suitable commodity for him to operate, capital profits can be optimized. And the result of optimization of capital profits is the increment of capital and the generally formation of brand.

\subsection{Conspiracy permeation--get stable income (Taurus Effect)}

For those operating areas which have great interest, operators and operators, even operators and university's some department may seek conspiracy permeation, in order to get maximum stable interest. Establishing national university's independent college, constructing students' dormitory, staffs' dormitory and fixed asserts, doing textbook business, marketing students' supplies and so on, all had the tendency of conspiracy permeation. During marketing operating strategy, operators and school interest group all are willing to invest on high profit areas, just like Boston matrix's Taurus type, certainly will became a conspiracy field of operators.

\subsection{The occupation campus economic--the marching in of investment and contract}

With the rise of a new round of university construction, no matter the national university or local public college all in varying degrees expand the campus, build schoolhouses, and add equipment. They make the university construction became a factor of the national or local GDP growth by rising loans or attracting investment. In the university construction agitation, because of lacking short-term funds, many universities have taken the way of attracting investors or contractors to operate. The marching in of investors and contractors is a long-term occupation of campus economy. No matter the right of land use or the lease fees of students' dormitory water heater, campus lost its control of them. And in a way, the operators and contractors deprive of the teachers and other staffs' economic welfare. The campus economic regime also made university which supposed without a commercial atmosphere became a slave that carrying debt burden and interest of lending. Once university has a debt, the leadership may be influenced by the investors or contractors in some extent, and thus has a difficult in making good economic decisions. On the other hand, investors and contractors can sit and enjoy a great benefit without hard work. From the phenomenon, it's common to see a professor with one hundred thousand Yuan a year, and an investor with a million Yuan a year.

\subsection{University shareholders--a forever winner}

Some national universities have also taken stock cooperative reform. Because of some historical or traditional reasons, some investors (or contractors) became shareholders in stock cooperative universities. There are specific forms, such as stock cooperative college, stock cooperative research institute, joint-stock system of teaching and research section, joint-stock system of laboratory and so on. Except for owning stocks, investors often also have the right of naming the object they invest. If the investors use the stock dividend for a continuing invest- 
ment to own more stocks, gradually national universities will loose their national identity in the near future. That is the time one became a university shareholder, his capital flow will grow bigger and bigger, and will never dry up.

\subsection{To maintain and increase their value-- operating university, hotel, hospital, and so on}

The capital flow of derivative economic circle's final goal is to maintain and increase value in a break-even point. The main carrier that use to maintain and increase value must equip several basic conditions, such as good operating skills, famed brand, strong cash flow, big interest space, high financial credit and so on. Private school, hotel, hospital, etc. mostly meet the conditions above, and that's why they often became the operating objects that used to maintain and interest values. So around the universities that have a long history, there are more high standard private schools, hotels, and various kinds of special hospitals. To match the situation, there are more financial institutions' management offices.

From the discussion above we can know that the capital flow of university's derivative economic circle is a moving subject that constructed by entrepreneurs' benefits. It can constantly increase during the integration with different operating level of university, and maximum the flow during the process of maintaining and increasing values. It is significant to economy and academic research.

\section{The development trend of derivative economic circle}

The derivative economic circle of university management is still in a sustainable development. In order to have the correct control of its developing trend, and make university operation became the weapon which can secure staffs' maximum benefits; we must take good use of derivative economic circle's special advance, and make it taking the correct way that be beneficial to university and local development.

\subsection{Positive induction}

University has entered a generation that needs management. The essential of management is to integrate al university resources, and make it taking the sustainable development direction. The positive inductions of derivative economic circle means sorting university's internal and external resources, and form a controllable economic operation mechanism, so that university and its secondary development subject (namely derivative economic circle) can develop in a harmonious and orderly way, and create a win-win situation.

Thus, in the medium and long-term development plan, university should list the using of external economy in the plan, and actively plan the market mechanism, establish project carrier, and encourage teachers and staffs to participate the formation of derivative economic circle, becoming the complementary economic level during university's development in the future. In addition, using the way of knowledge integration and industry planning to plan the university's internal and external economic development is an important way of positive induction.

\subsection{Reverse hatching}

Universities taking the advance of strong cash flow, (break through policy limit) start from the important carriers that can maintain and interest values, effectively operate schools, hotels, hospitals and so on, enter derivative economic circle in reverse way. Then by using the merging strategy, universities make each level of derivative circle operated under the development of the main body. What's more, establishing market system around university through government plan, making university have the prior right of operating, can also make university enter the derivative economic circle quickly and become an important reverse thrust of reverse hatching.

The goal of reverse hatching still is to let the inside and outside operators achieve win-win and multi-wins. Its method is defending the final line and break through from big capital. Since universities have a big cash flow, thus have a bigger advantage than any other non-financial enterprises, they can use these advantage to occupy the market, and gradually weaken non-national operating subjects' position in derivative economic circle. And then their reverse hatching effect will be unprecedented significant.

\section{References}

1. Jiang Xinxi, Cheng Hao. An approach to knowledge economics of universities [J]. Journal of Jiangxi Normal University (Social Sciences), 2009, 42(4).

2. Huang Boyun. Improve the innovative ability strong talent team construction [J]. Chinese Higher Education, 2006, (5).

3. Huang Boyun. To establish a modern university Chinese independent innovation system [J]. China Tungsten Industry, 2007, (1).

4. Jiang Xinxi. Research and Development of Economics [M]. Stream Publishing of Japan Hiroshima, 1994. 